\title{
Predictability of intense rain storms in the Central Mediterraneanbasin: sensitivity to upper-level forcing
}

\author{
S. Federico ${ }^{1,2}$, E. Avolio ${ }^{1,3}$, C. Bellecci ${ }^{1,3}$, A. Lavagnini ${ }^{2}$, and R. L. Walko ${ }^{4}$ \\ ${ }^{1}$ CRATI Scrl, c/o Università della Calabria, Rende (CS), Italy \\ ${ }^{2}$ CNR-ISAC, via del Fosso del Cavaliere 100, Rome, Italy \\ ${ }^{3}$ Facoltà di Ingegneria-Università di “Tor Vergata”, via del Politecnico 1, Rome , Italy \\ ${ }^{4}$ Pratt School, Duke University, Durham, NC, USA
}

Received: 6 January 2007 - Revised: 15 March 2007 - Accepted: 13 May 2007 - Published: 26 June 2007

\begin{abstract}
This study investigates the sensitivity of a moderate-intense storm that occurred over Calabria, southern Italy, to upper-tropospheric forcing from a Potential Vorticity (PV) perspective. A prominent mid-troposheric trough can be identified for this event, which occurred between 22-24 May 2002, and serves as the precursor agent for the moderate-intense precipitation recorded.

The working hypothesis is that the uncertainty in the representation of the upper-level disturbance has a major impact on the precipitation forecast and we test the hypothesis in a two-step approach. First, we examine the degree of uncertainty by comparing five different scenarios in a Limited area model Ensemble Prediction System (LEPS) framework which utilizes the height of the dynamical tropopause as the discriminating variable. Pseudo water vapour images of different scenarios are compared to the corresponding METEOSAT 7 water vapour image at a specific time, antecedent to the rain occurrence over Calabria, in order to evaluate the reliability of the different precipitation scenarios simulated by the LEPS.

Second, we examine the impact of upper tropospheric PV variations on precipitation by comparing model simulations with slightly different initial PV fields. Initial velocity and mass fields in each case are balanced with the chosen PV perturbation using a PV inversion technique. The results of this study support the working hypothesis.
\end{abstract}

\section{Introduction}

The Mediterranean region is often characterized by torrential rainfall and flash floods at different spatial and temporal scales (Siccardi, 1996). Several cases have been studied, discussed and reported in different countries around the basin

Correspondence to: S. Federico

(s.federico@crati.it)
(Homar et al., 2001; Fehlman et al., 2000; Buzzi and Foschini, 2000; Alpert et al., 2002). The most intense precipitation events are usually associated with dynamical structures of different spatial and temporal scales such as synoptic scale cyclones and sub-synoptic mesoscale vortices.

The most common type of intense cyclones in the Mediterranean region is the baroclinic lee cyclone of the type described in Buzzi and Tibaldi (1978). Such cyclones can be quite intense over Calabria as its peculiar geographical feature, i.e. the presence of a warm sea nearby steep mountainous ranges, can determine persistent precipitation pattern over localized spots (Federico et al., 2003).

In the extra-tropical atmosphere, intense cyclones often develop under upper-tropospheric jet streams that are frequently characterized by anomalously high values of Potential Vorticity (PV). PV is conserved along the flow on an isentropic surface under adiabatic and frictionless conditions (Hoskins et al., 1985). Because of its conservative property, PV is used to trace areas with specific air mass characteristics, and is applied in the analysis of atmospheric processes. The PV positive anomalies associated with jets (PV streamers) influence the timing, amplitude and location of intense surface cyclones and heavy precipitation events by uppertropospheric forcing (Fehlman and Davies, 1999; Fehlman et al., 2000; Krichack et al., 2007). Accurate specification of the troposphere PV distribution might be a necessary prerequisite for the successful prediction of hazardous weather events (Romero et al., 2005; Romero et al., 2006).

The aims of this study are: (1) to suggest a new subjective approach for improving an existing forecast; (2) to evaluate the sensitivity of the prediction of a moderately intense rainstorm that occurred on 22-24 May 2002 over Calabria to the accuracy of the model description of the uppertroposphere effects. In particular, this study suggests an optimized methodology, based on the comparison between METEOSAT water vapour (WV) images and the model output WV pseudo-images, to subjectively improve the forecast.

Published by Copernicus Publications on behalf of the European Geosciences Union. 


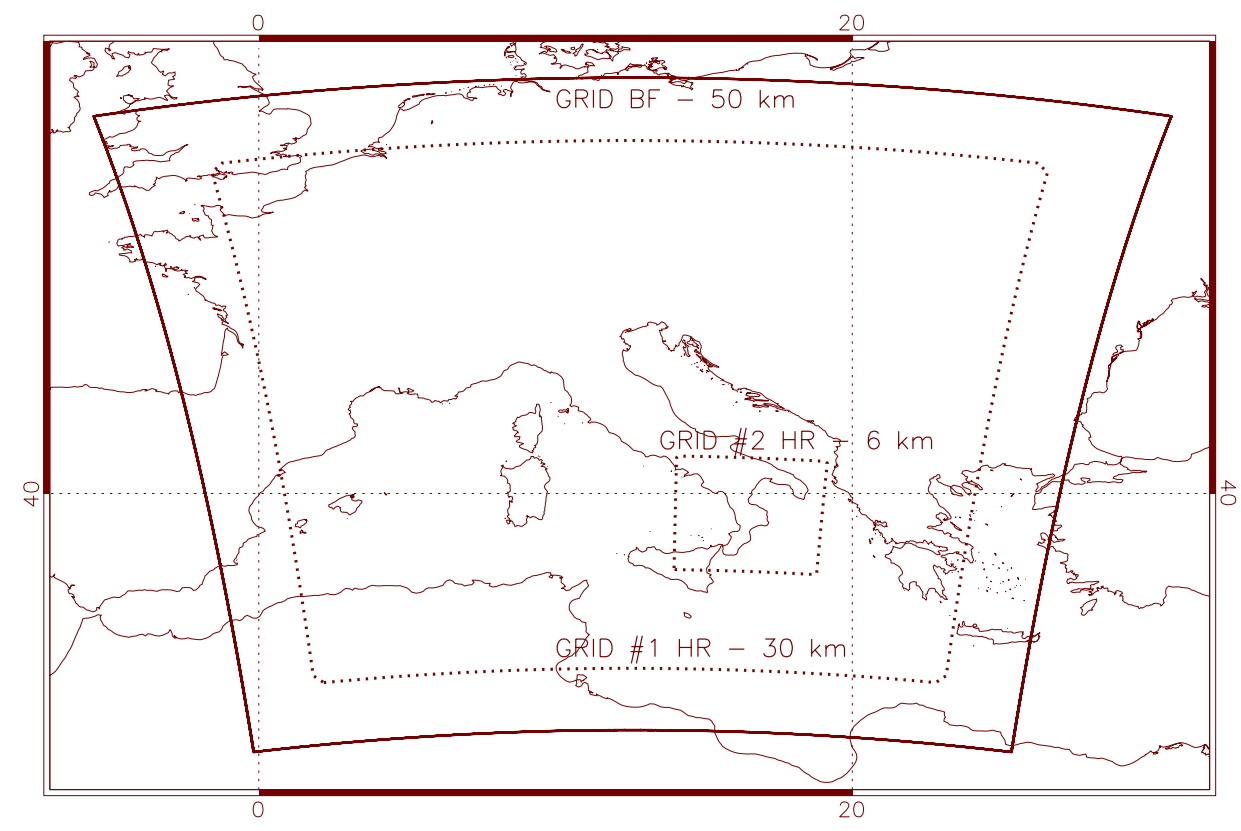

Fig. 1. Domain configuration. The outermost grid is used for the RAMS-BF approach with $50 \mathrm{~km}$ horizontal resolution. The other two grids are used for the RAMS-HR configuration and their horizontal grid spacings are $30 \mathrm{~km}$ and $6 \mathrm{~km}$.

\section{Methodology}

The strategy adopted to study the sensitivity of the storm to the meteorological large scale patterns and to examine its predictability consists of generating different "scenarios" respect to a reference run (hereafter also referred as control). In this approach we assume that the model is "perfect" and that the major error sources are associated with deficiencies in the knowledge of initial conditions ingested into the mesoscale model, a real problem in the data void Mediterranean region. We utilize a LEPS approach which is a two-step methodology:

1. Five sets of perturbed initial and boundary conditions ("scenarios") are generated by a hierarchical clustering technique applied to the results of a Brute Force (BF) run performed by the RAMS model (Cotton et al., 2003) with $50 \mathrm{~km}$ horizontal resolution. More in detail, we perform 51 runs of the Limited Area Model (LAM) driven by the 51 global predictions of the ECMWF-EPS (European Centre for Medium-range Weather ForecastEnsemble Prediction System), then we gather those runs following the methodology discussed later on in this section. RAMS-BF simulations enhance the vertical resolution in the troposphere and lower stratosphere compared to the ECMWF-EPS and are utilized to compute derived variables as $\mathrm{PV}$ or the height of the dynamical tropopause.

2. For each of the five "scenarios", a high resolution (HR) RAMS forecast, with $6 \mathrm{~km}$ maximum horizontal reso- lution, is performed to resolve local scales which have a high impact on local weather and are not represented properly in the ECMWF-EPS because of its coarse horizontal resolution. For this case study the horizontal resolution of ECMWF-EPS analysis and forecast cycle is $T_{L} 255$, which corresponds to about $80 \mathrm{~km}$ grid-point spacing.

Figure 1 shows the horizontal domains used by RAMS$\mathrm{BF}$ and RAMS-HR. The former model configuration utilizes one grid with $50 \mathrm{~km}$ horizontal resolution whilst the latter has two two-way nested grids having $30 \mathrm{~km}$ and $6 \mathrm{~km}$ horizontal resolutions. Both LAM configurations use thirty vertical levels, up to $16000 \mathrm{~m}$ in the terrain following coordinate system. Levels are not equally spaced: within the PBL (Planetary Boundary Layer) the layer thickness ranges between $50 \mathrm{~m}$ and $200 \mathrm{~m}$, while in the middle and upper troposphere it gradually increases from 700 to $1000 \mathrm{~m}$.

The methodology adopted to cluster the RAMS-BF members and to select the Representative Member (RM) from each cluster is a hierarchical clustering technique which is based on a PV perspective. For the extra-tropics, PV values above $3 \mathrm{PV}$ units ( $1 \mathrm{PV}$ unit is $10^{-6} \mathrm{~K} \mathrm{~kg}^{-1} \mathrm{~m}^{2} \mathrm{~s}^{-1}$ ) are inferred to represent stratospheric air masses because of the high values of static stability in this portion of the atmosphere. PV values of 1.5-3 PV units represent air that originated near the tropopause. PV values less than $1.5 \mathrm{PV}$ units represent tropospheric air masses. Following this classification, the height of the $1.5 \mathrm{PV}$ units surface represents the height of the dynamical tropopause. 


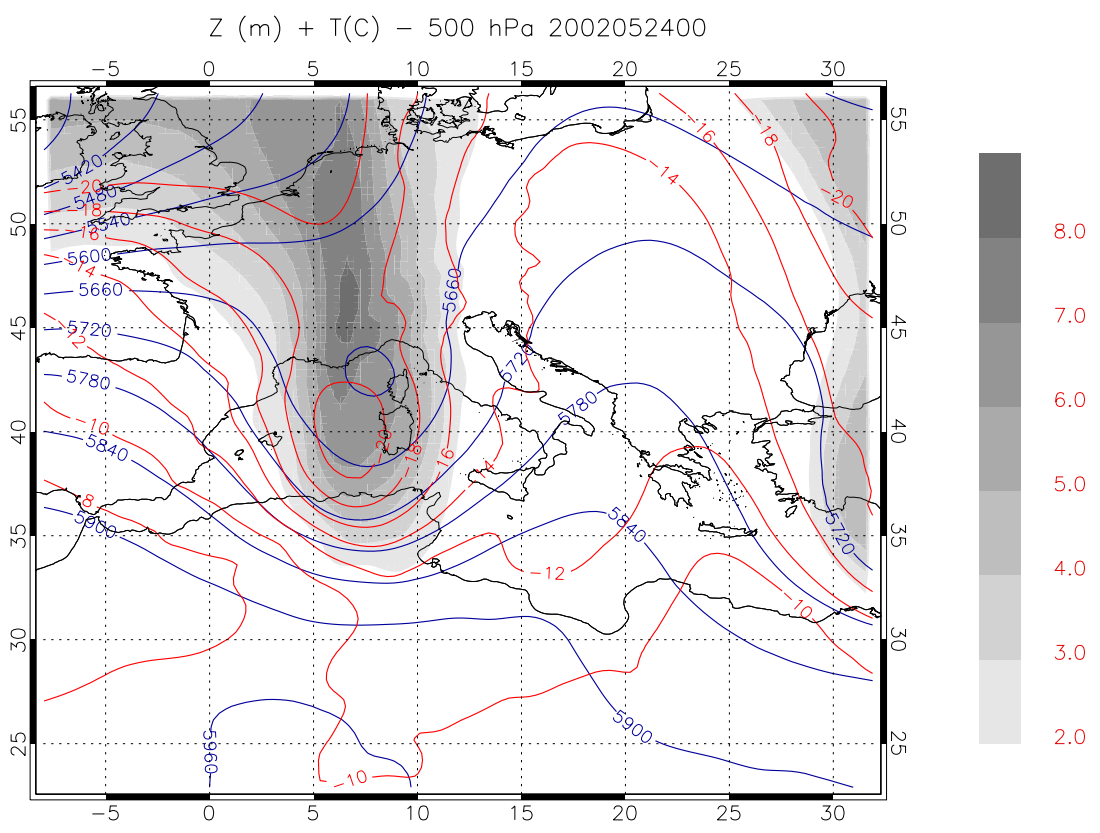

Fig. 2a. Potential vorticity (PVU, shaded contours) at $250 \mathrm{hPa}$, geopotential height (gpm, solid blue line) and temperature $\left({ }^{\circ} \mathrm{C}\right.$, solid red line) at $500 \mathrm{hPa}$ on 00:00 UTC 24 May 2002.

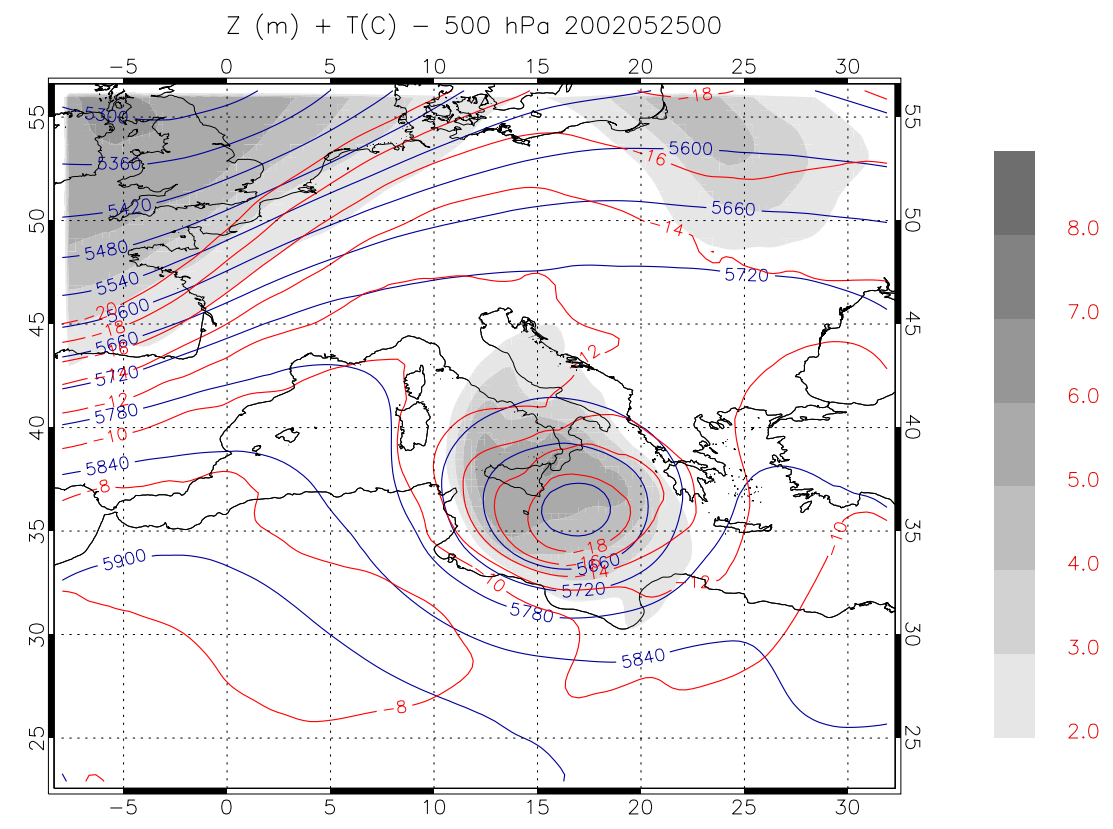

Fig. 2b. As in Fig. 2a at 00:00 UTC on 25 May 2002.

In this work we adopt the height of the dynamical tropopause as the discriminating variable in the clustering technique. This height is computed for each RAMS-BF member, for each grid point and for all available time outputs. The frequency of the model output is $6 \mathrm{~h}$. In particular, after defining a suitable set of potential temperature levels, we compute the isentropic coordinate version of the PV by the expression:

$\mathrm{PV}=\sigma^{-1} \xi_{a \vartheta}$

where $\sigma=-g^{-1} \frac{\partial p}{\partial \vartheta}>0$ is the air mass density in $x y \theta$ space, $\theta$ is the potential temperature, $p$ is the pressure, $g$ is the acceleration due to the gravity, $\xi_{a \vartheta}=f+\xi_{\vartheta}$ is the absolute isentropic vorticity, $\xi_{\vartheta}=\left(\frac{\partial v}{\partial x}-\frac{\partial u}{\partial y}\right)_{\vartheta}$ and $u$ and $v$ are the zonal 


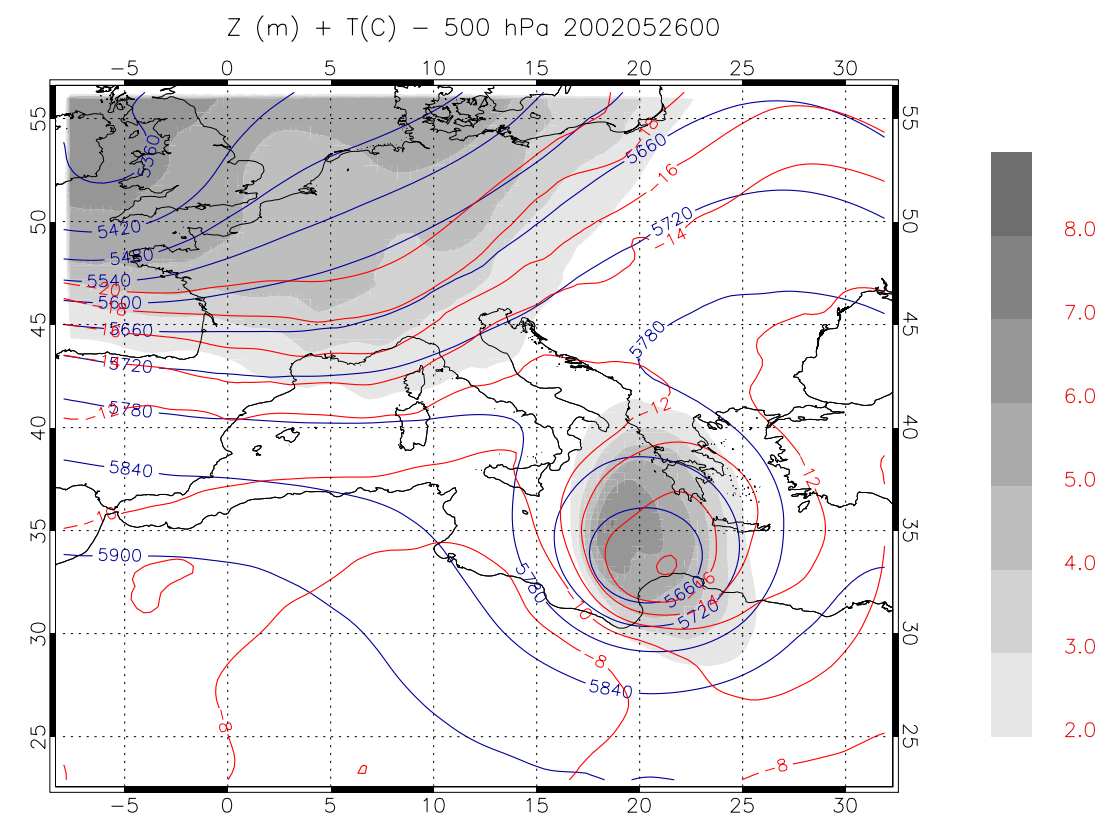

Fig. 2c. As in Fig. 2a at 00:00 UTC on 26 May 2002.

and meridional velocity components. Finally the height of the dynamical tropopause is given by the model height corresponding to $\mathrm{PV}=1.5 \mathrm{PVU}$. Once the heights of the dynamical tropopause for each RAMS-BF member have been calculated, the clustering methodology is as follows.

1. We begin with 51 clusters where each RAMS-BF member belongs to one cluster.

2. From $t_{0}+24 \mathrm{~h}$ to $t_{0}+84 \mathrm{~h}$, where $t_{0}$ is the initial simulation time, we calculate the space-averaged quadratic distances between all RAMS-BF members for the height of the dynamical tropopause. The spaceaveraged quadratic distance between RAMS-BF members $k$ and $l$, at time $t$, is given by:

$d(t)=\frac{1}{N} \sum_{i=1}^{N}\left(\operatorname{hgt}_{k}(i)-\operatorname{hgt}_{l}(i)\right)^{2}$

where $h g t_{k}$ and $h g t_{l}$ are the heights of the dynamical tropopause for the members $k$ and $l$, respectively, and the summation spans all grid points inside the central Mediterranean basin $(5 \mathrm{E}-20 \mathrm{E} ; 35 \mathrm{~N}-45 \mathrm{~N})$. The distance between members $k$ and $l$ is then determined by averaging (2) over all available model outputs from $t_{0}+24 \mathrm{~h}$ to $t_{0}+84 \mathrm{~h}$.

3. The two clusters having the minimum distance are grouped together.

4. Next, we calculate distances between different clusters by averaging distances between all cluster members.

5. Steps 3 and 4 are repeated until only five clusters remain.
6. One RM is selected for each of the five clusters by minimizing the ratio between the distance from its own cluster members and the distance from members belonging to other clusters.

7. Finally, five RAMS-HR simulations are performed driven by the ECMWF-EPS data corresponding to each RM.

Before concluding the section, we remark that ECMWF-EPS did not perform very well for this case study and none of the 51 members of the ECMWF-EPS forecasts was able to describe the real development of the storm. More in detail, the ECMWF-EPS ensemble mean precipitation over Calabria has values less than $10 \mathrm{~mm}$ and the probability map of rainfall larger than $10 \mathrm{~mm}$ is less than $15 \%$ everywhere over the country. These values are far less than observed precipitation amounts, which are presented in Sect. 4. This is at least partially confirmed by the poor performance of the RAMS-BF ensemble mean and probability maps, as discussed in more detail in Federico et al. (2006).

\section{Model set-up}

The following is a brief description of the model set up including options selected. For details on RAMS model the reader should refer to Cotton et al. (2003).

Horizontal and vertical grids have been introduced in the previous section. Parameterization of surface-atmosphere diabatic processes is described in Walko et al. (2000). Nonconvective precipitation is computed from explicit prognostic equations for seven hydrometeor categories: cloud 


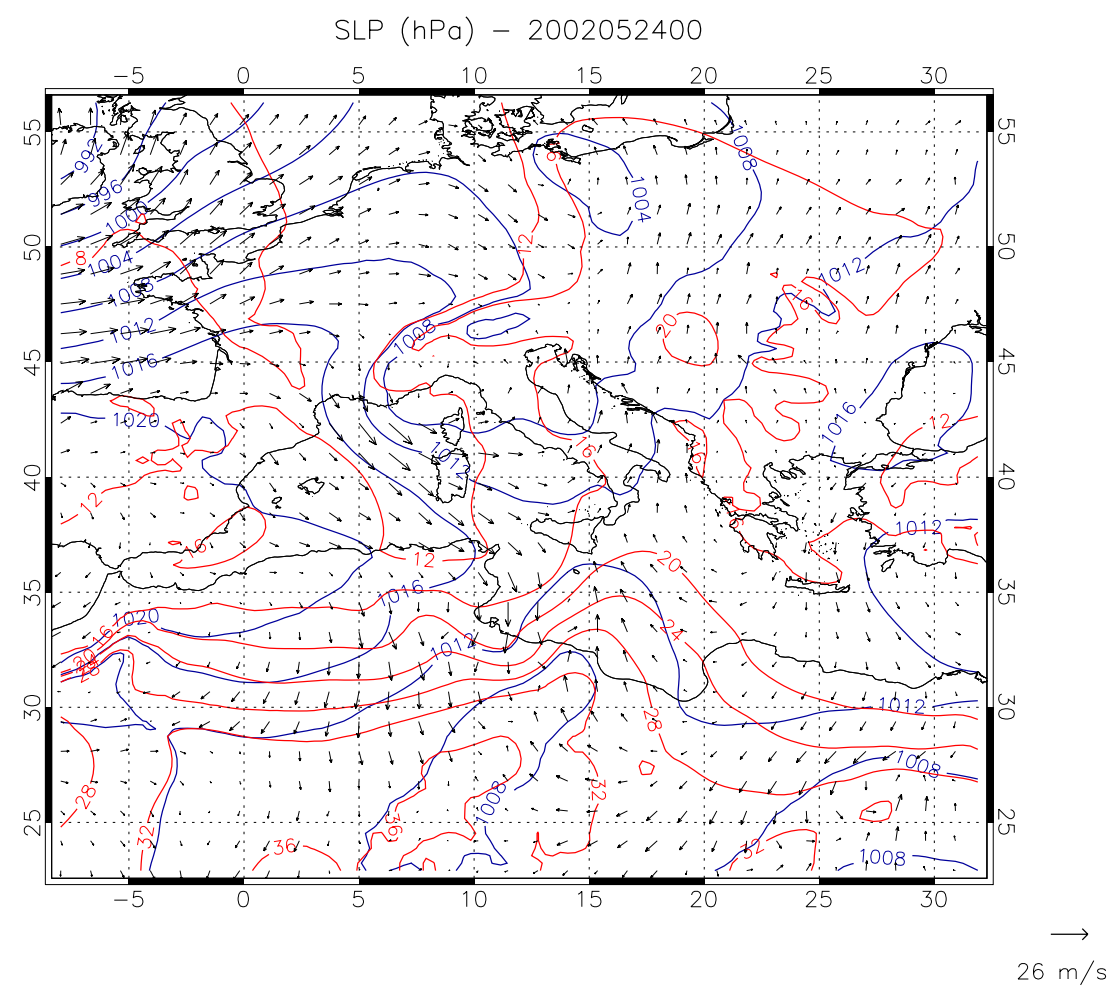

Fig. 3a. Sea level pressure (hPa, solid blue line), wind vectors, and temperature $\left({ }^{\circ} \mathrm{C}\right.$, solid red line) at $925 \mathrm{hPa}$ at 00:00 UTC on 24 May 2002.

Table 1. Results of the application of the hierarchical clustering technique to the case study. The first column is the cluster number, the second shows the cluster population, i.e. the number of RAMS$\mathrm{BF}$ members belonging to each cluster, the third the Representative Member.

\begin{tabular}{ccc}
\hline Cluster \# & Elements \# & RM \\
\hline 1 & 22 & 3 \\
2 & 18 & 43 \\
3 & 8 & 38 \\
4 & 1 & 8 \\
5 & 2 & 50 \\
\hline
\end{tabular}

droplets, rain, pristine ice, snow, aggregates, graupel, and hail. Hydrometeor sizes are assumed to follow a generalized gamma distribution. Convective precipitation is parameterized following Molinari and Corsetti (1985) who proposed a simplified form of the Kuo scheme that accounts for updrafts and downdrafts.

All simulations presented for this case study start at 12:00 UTC on 22 May and last $84 \mathrm{~h}$.

\section{Results}

We first give a short overview of the event based on the ECMWF analysis available on a $0.5^{\circ}$ horizontal grid at standard pressure levels every $6 \mathrm{~h}$. Figure $2 \mathrm{a}$ shows the $500 \mathrm{hPa}$ geopotential height, the $500 \mathrm{hPa}$ temperature and the $\mathrm{PV}$ as diagnosed from the analysis at $250 \mathrm{hPa}$ at 00:00 UTC on 24 May. An intense north-south PV streamer, associated with a mid-tropospheric deep trough, extends from the North Sea to the Mediterranean, crossing Europe roughly along the German-French border. A cutoff has already developed as a consequence of the interaction between the deep trough and western Alps, so this storm can be classified as a baroclinic cyclone formed on the lee of the Alps (Buzzi and Tibaldi, 1978). During the following $24 \mathrm{~h}$, the northern half of the PV streamer advected quickly to the northeast whereas the southern half remained more to the west crossing the Tyrrhenian sea from northwest to southeast. The situation $24 \mathrm{~h}$ later, i.e. at 00:00 UTC on 25 May, is shown in Fig. 2b. At this time the cutoff has already crossed Calabria and Sicily. Over the following $12 \mathrm{~h}$ the cold cutoff remained almost stationary over the Ionian Sea, and then it moved toward southeast. Figure 2c shows the situation at 00:00 UTC on 26 May. The cutoff low is still active on the northern Libyan coast, but by this time the precipitation over Calabria has already ceased. 


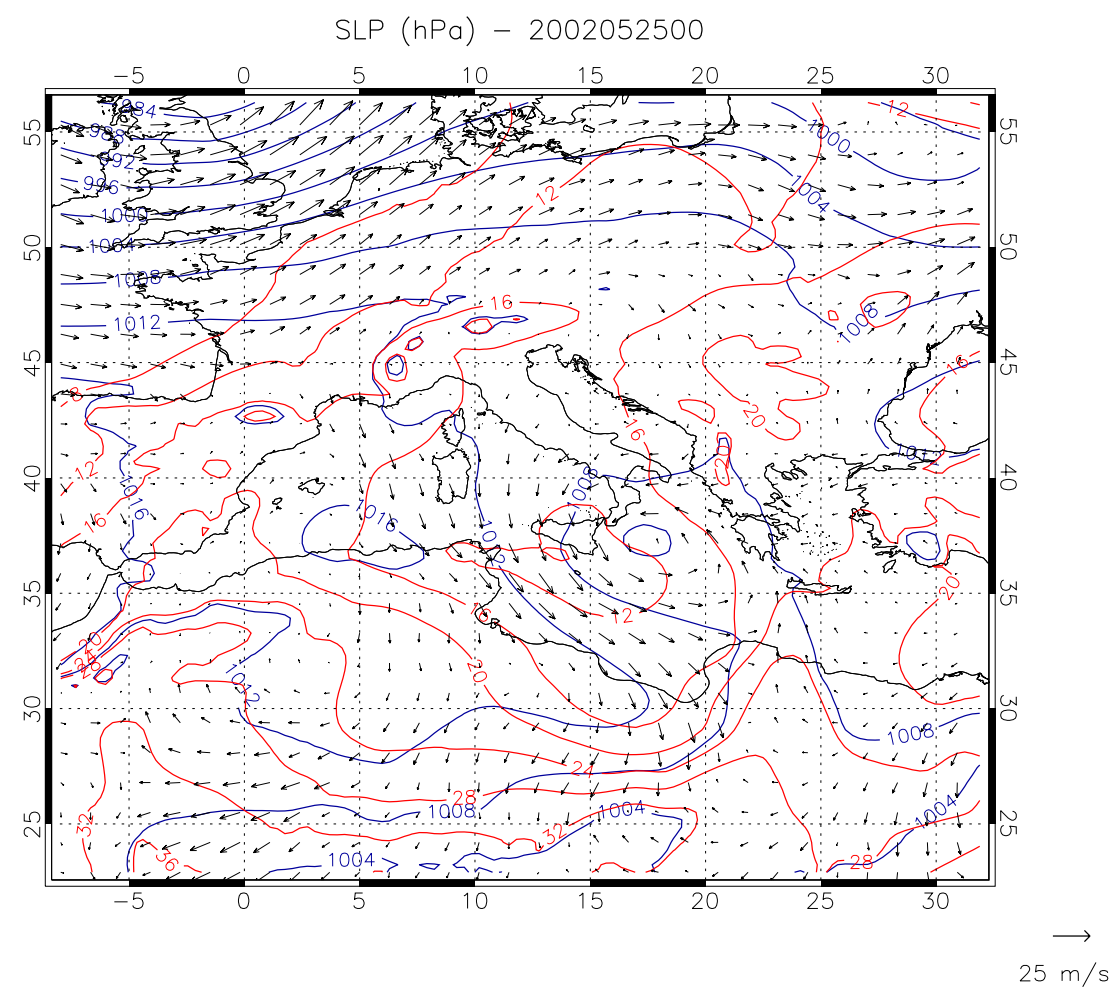

Fig. 3b. As in Fig. 3a on 25 May 2002.

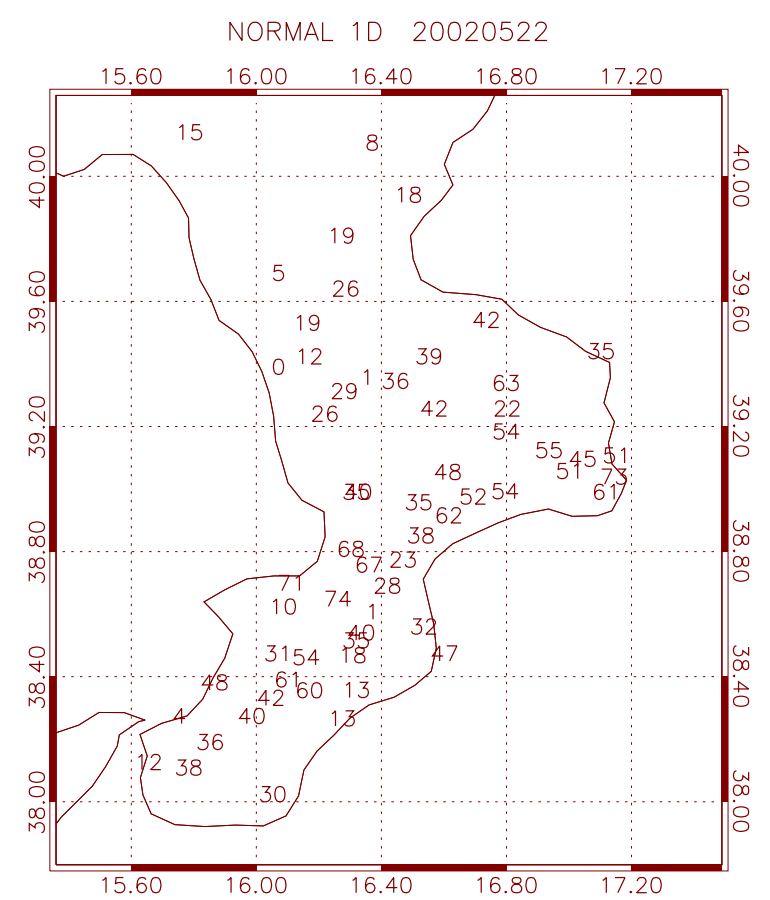

Fig. 4. Total rainfall recorded by the Calabrian regional network from 18:00 UTC 24 May to 00:00 UTC 26 May 2002.
The low level analysis corresponding to Fig. 2a, i.e. at 00:00 UTC on 24 May, is presented in Fig. 3a. A surface pressure minimum is developing over the Gulf of Genoa as the upper level cutoff forms. The sea level pressure pattern forces a rather intense flow over the Tyrrhenian Sea from west-northwest and a surface flow from the south toward the eastern Calabrian coast. Surface air parcels follow a remarkably long fetch over the sea before reaching Calabrian coasts, where they interact with local orographic barriers.

Figure $3 b$ shows the surface analysis at 00:00 UTC on 25 May. As the upper level cold low crosses Sicily and Calabria, the surface low deepens, aided by interaction with local orographic barriers, and a mesolow forms over the Ionian sea. The surface flow toward the Calabrian Ionian coast is mainly from the east-northeast and remains almost stationary for $12 \mathrm{~h}$, as already noted for the upper level flow.

The development of the subsynoptic low over the Ionian sea is one of the mesoscale ingredient of this case study, and a careful inspection of RMs outputs reveals that the precipitation over Calabria is very sensitive to the location and intensity of the mesolow. Moreover, the rainfall sensitivity to this feature is amplified by the complex orography of Calabria where steep mountains are located by the sea along the entire peninsula. The cyclonic moist flow established on the Ionian sea impinges the east Calabrian littoral and provides a continuous supply of moist and warm air toward the coast. Warm and humid air masses interact with local orography that influences precipitation location and intensity. 


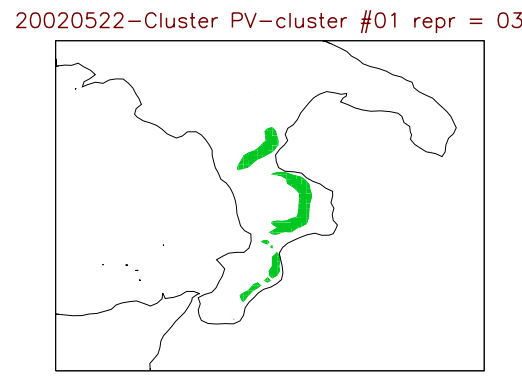

20020522-Cluster PV-cluster \#03 repr $=38$

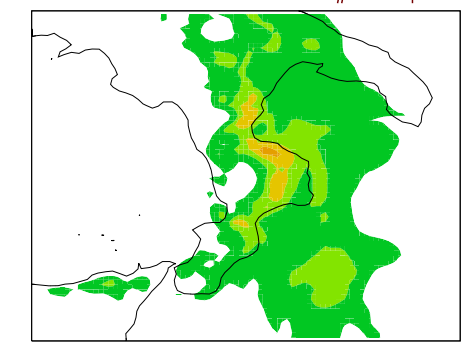

20020522-Cluster PV-cluster \#05 repr $=50$

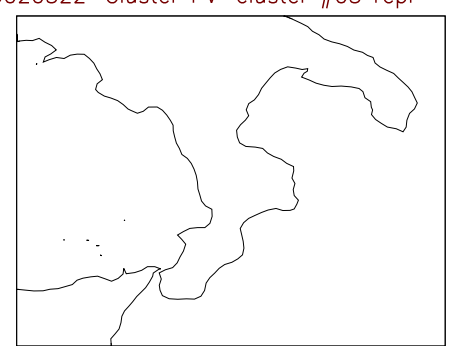

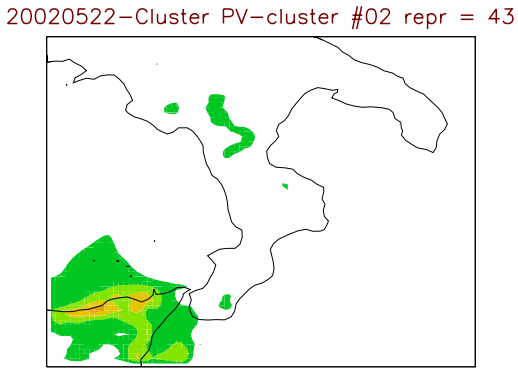

20020522-Cluster PV-cluster \#04 repr = 08

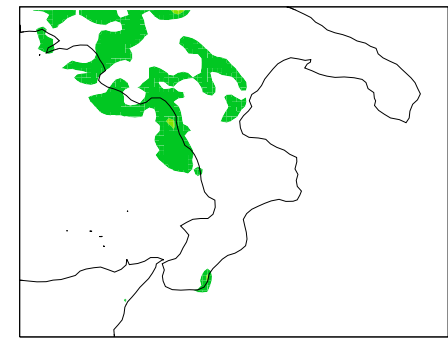

20020522-Cluster PV-cluster \#06 repr $=00$

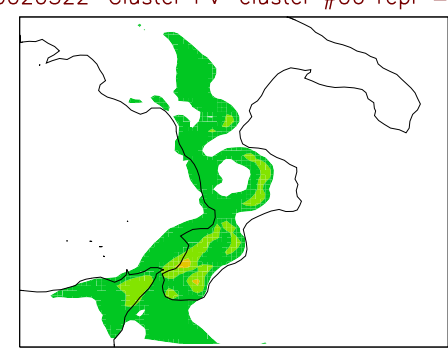

300.0

275.0

250.0

225.0

200.0

175.0

150.0

125.0

100.0

75.0

50.0

25.0

Fig. 5. Total accumulated precipitation over the same time frame as Fig. 4 for the RMs high resolution simulations, together with the control run. The RM number is reported on each panel (upper right corner).

Figure 4 shows the total rainfall recorded by the Calabrian regional raingauge network. There are two main precipitation spells. The first one is located on the east side of the country, the second one affected the southeast of the peninsula. Throughout the event the main flow was from east or southeast and both spells show an orographic component because the most abundant precipitation is recorded upstream of the main peaks. Rainfall over Calabria started at 18:00 UTC on 24 May and lasted about $30 \mathrm{~h}$.

The clustering technique produces the five clusters reported in Table 1. The unperturbed forecast (hereafter also referred to as 00) belongs to the first cluster. In the following discussion we prefer to consider the ECMWF-EPS numeration because it is more general than our cluster numeration (1-5), whose members depend on the clustering technique.

For each RM a high resolution RAMS forecast is performed. Figure 5 reports the total accumulated precipitation, during the same time period as Fig. 4, for the RMs high resolution simulations, together with the control run. Filled contours are the same for all plots. With the exception of member 38 and, partially of the reference run, all RMs underestimate rainfall for the event presented. This feature, al- ready reported in Federico et al. (2006) for different clustering variables, confirms that LEPS performs rather poorly for this case study because rainfall amount is appreciably underestimated by the majority of the RMs.

\subsection{The subjective comparison between RAMS WV pseudo-images and the corresponding METEOSAT 7 WV image}

The PV perspective adopted here allows a unique chance to discuss the different precipitation fields simulated for the RMs because these patterns, in terms of amplitude, timing and distribution, are reflected in the structure of the upper level PV filament. In the following discussion, for brevity, we report results for the unperturbed forecast and for the RMs 38, 50 and 43. Figure 6a shows the METEOSAT 7 water vapour (WV) image for 12:00 UTC on 24 May while Figs. $6 \mathrm{~b}, \mathrm{c}, \mathrm{d}$ and e are the pseudo water vapour (PWV) images for the 00 forecast and for the RMs 38, 43 and 50. Figures $6 \mathrm{~b}$-e show the temperature $\left({ }^{\circ} \mathrm{C}\right)$ on a water vapour isosteric surface with specific humidity of $75 \mathrm{mg} / \mathrm{kg}$. 


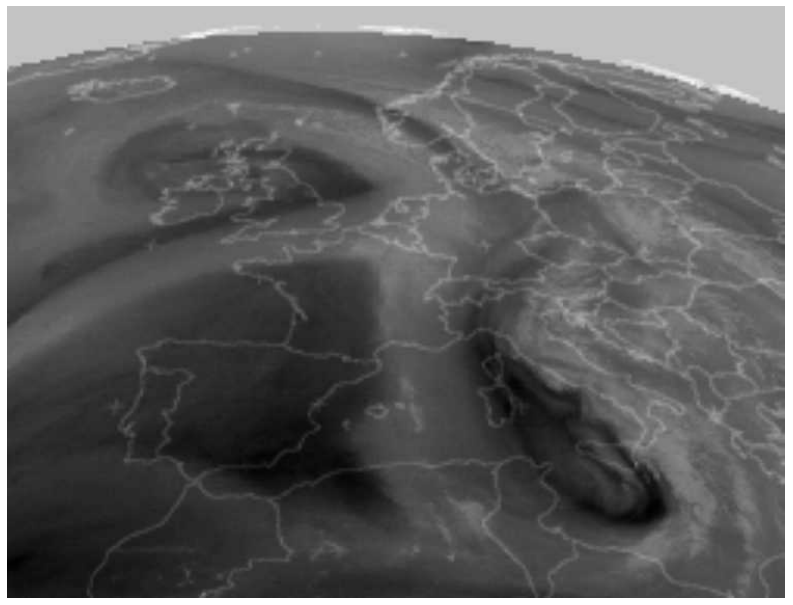

Fig. 6a. METEOSAT 7 WV image for 12:00 UTC 24 May 2002.

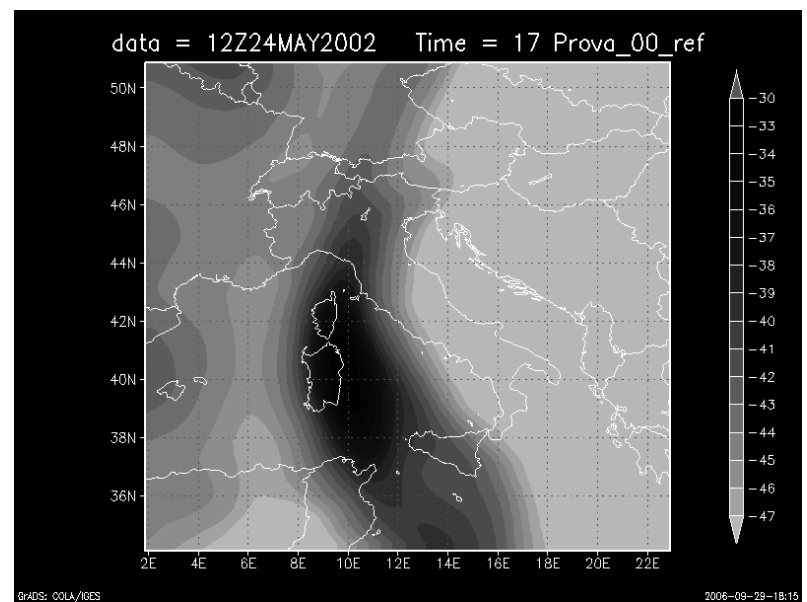

Fig. 6b. RAMS pseudo WV image for 12:00 UTC 24 May 2002 for the unperturbed forecast. The image has been derived from the HR forecast. The plotted field is the temperature $\left({ }^{\circ} \mathrm{C}\right)$ of the $75 \mathrm{mg} / \mathrm{kg}$ isosteric surface.

It may be noted that comparison between those images is meaningful only for cloud free regions. An inspection of the corresponding METEOSAT 7 visible and infrared images (not shown) reveals that almost all the Tyrrhenian Sea bounded by the Italian peninsula and Sardinia and Corsica islands was a cloud free region.

Comparison between Figs. $6 \mathrm{a}$ and $\mathrm{b}$ reveals that the unperturbed forecast is only partially satisfactory at this simulation time, i.e. $48 \mathrm{~h}$ after the initial time. The westernmost part of the PV anomaly is well represented by the simulation that misses its easternmost more advanced portion. However, there is a good agreement between the model PWV and the METEOSAT 7 images for the PV streamer.

Figure $6 \mathrm{c}$ shows a more complex pattern: the fine structure and the position of the dark band are well represented by the RM 38. In particular the more advanced portion of the PV

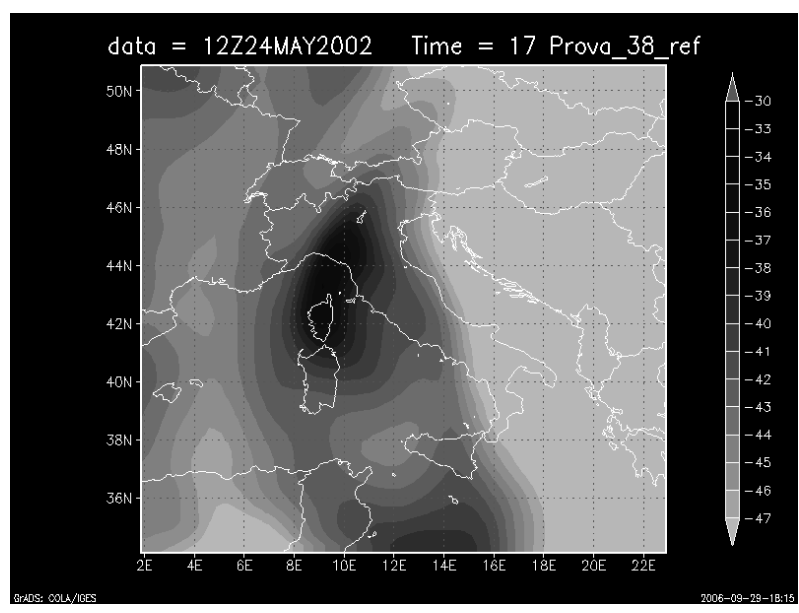

Fig. 6c. As in Fig. $6 \mathrm{~b}$ for the RM 38.

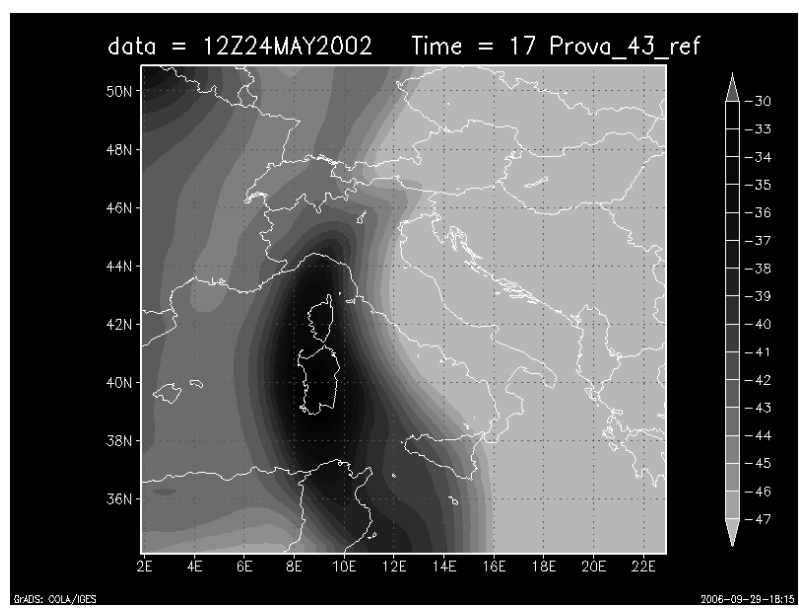

Fig. 6d. As in Fig. 6b for the RM 43.

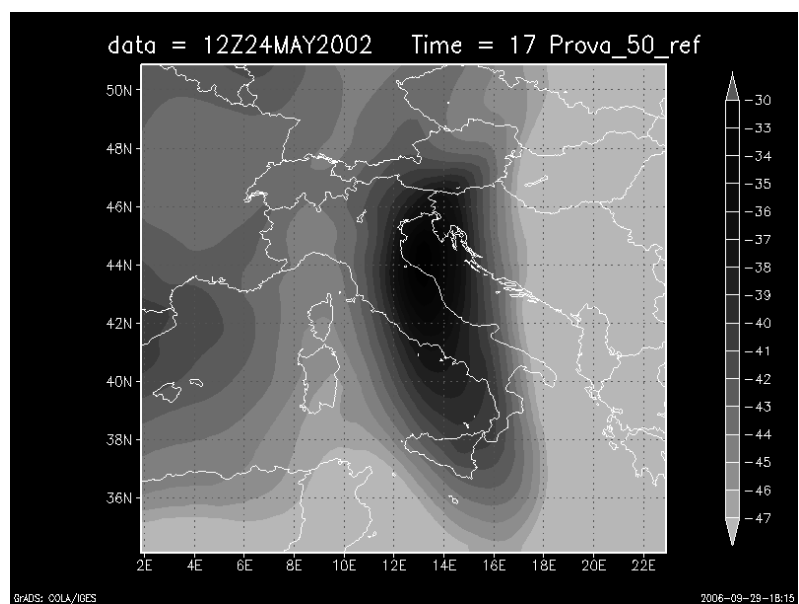

Fig. 6e. As in Fig. $6 \mathrm{~b}$ for the RM 50. 


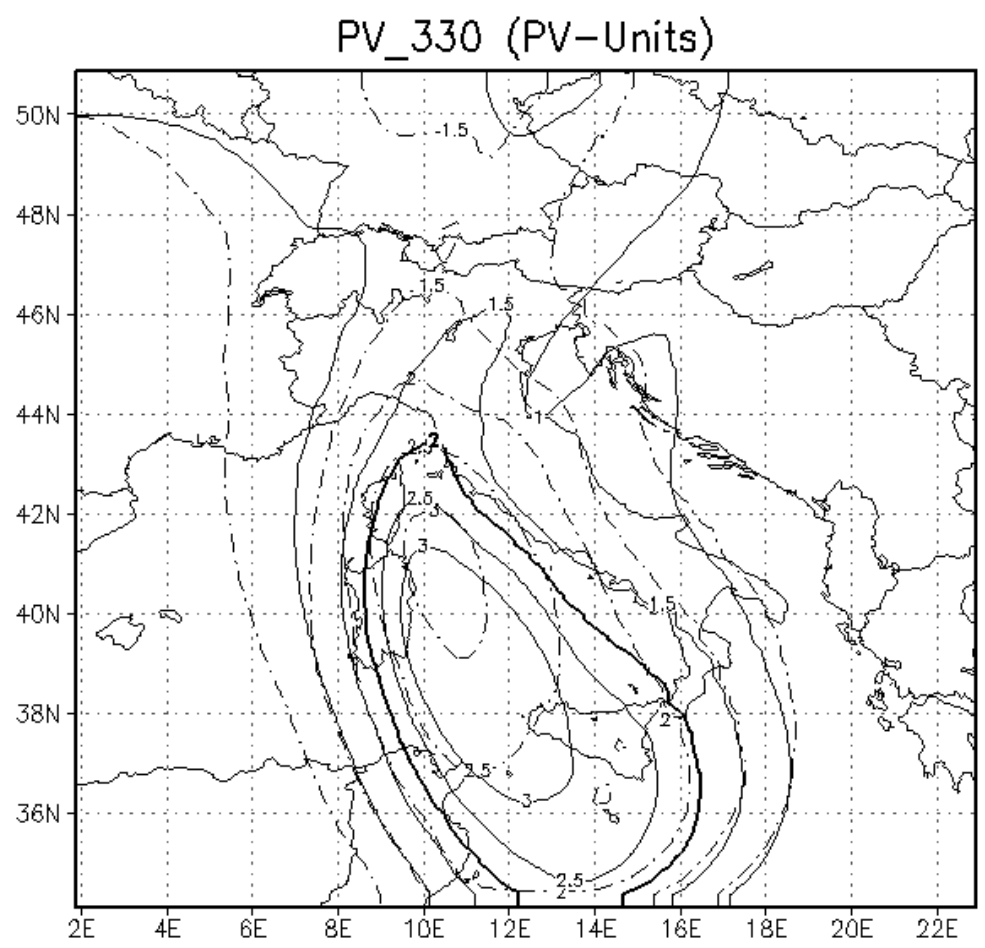

GRADS: COLA/IGES

Fig. 7. PV contours for the unperturbed forecast (solid contours) and for the RM 38 (dot dashed contour). PV is on the $330 \mathrm{~K}$ surface. Contours from 1.0 to 3.0 PVU are shown every 0.5 PVU. Thick solid line identifies the shape of the PV filaments inverted above $500 \mathrm{hPa}$.

anomaly and its structure over the Tyrrhenian Sea is better represented compared to the unperturbed forecast. At the same time the structure of the PV filament over Sardinia is not so well represented as in the unperturbed forecast.

Figure $6 \mathrm{~d}$ has a pattern similar to the reference case but it is shifted to the west. This is a consequence of a time delay between the control and RM 43. This delay is also suggested by Fig. 5. Precipitation amount is well represented by the RM 43 but its location is over Sicily, i.e. too far to the west compared to measurements available for Calabria. Moreover comparison between METEOSAT 7 and RM 43 for 15:00 UTC (not presented) indicates that the delay is increasing for the RM 43 as the simulation goes on.

Comparison between RM 50 PWV image, Fig. 6e, and the control simulation shows that the PV filament structure is completely missed by this RM. Indeed the dark band in RM 50 is about $500 \mathrm{~km}$ to the east of the METEOSAT WV image and we conclude that this forecast should be discarded.

From the qualitative-subjective analysis presented above we conclude that none of the scenarios simulated by LEPS is completely satisfactory compared to the METEOSAT $7 \mathrm{WV}$ image. However the PV perspective adopted in this work would have clearly improved the LEPS forecast through the qualitative comparison presented above. Scenarios of RM 43 and 50 and their respective clusters would have been discarded, because their PWV maps do not resemble the corre- sponding METEOSAT image. Comparatively, the scenario 38 and the reference scenario, and their associated precipitation fields, would have been considered more likely, if the maps of Fig. 6 had been available, because there is a better qualitative agreement between PWV images and the corresponding METEOSAT WV scene.

\subsection{Sensitivity to upper level tropospheric structure}

A second issue discussed in this study is the sensitivity of the event to upper level forcing, associated with the PV filament. A closer inspection of control and RM 38 precipitation forecasts, Fig. 5, shows that: a) the unperturbed forecast misses the precipitation on the Ionian side of Calabria, while it is able to represent rainfall on the western and southern part of the peninsula; b) the RM 38 gives a better forecast on the east side but it misses the precipitation spot in southern Calabria.

Our working hypothesis is that precipitation pattern is sensible to the mesoscale structure of the upper-tropospheric PV filament. To verify this hypothesis we perform a pseudo forecast in which an artificial initial state is generated at 12:00 UTC on 24 May for the RM 38 forecast. This state serves as the initial condition to simulate atmospheric developments during the following $36 \mathrm{~h}$, characterized by the rainfall over Calabria. The difference between initial conditions for the RM 38 and RM 38p (perturbed simulation 38) 


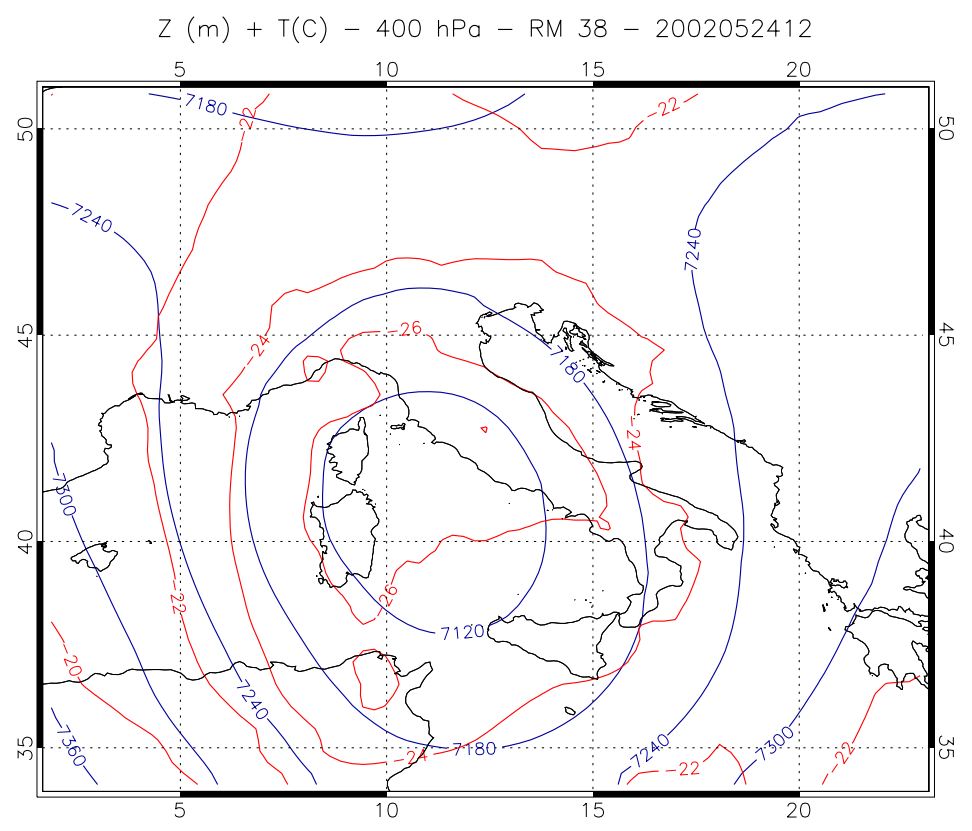

Fig. 8a. Geopotential height (m, blue line) and temperature $\left({ }^{\circ} \mathrm{C}\right.$, red line) at $400 \mathrm{hPa}$ on 12:00 UTC, 24 May 2002 for the RM 38 forecast.

is obtained in the following way. First we select a PV element from the difference between the PV fields for the unperturbed forecast and the RM 38, and then we invert the PV element and add the resulting signature to the RM 38 to obtain the perturbed analysis field for RM $38 p$ simulation. Finally we perform a new pseudo forecast starting from the perturbed analyzed field. To avoid an excessive shock in the perturbed run, we nudge the perturbed analysis for $6 \mathrm{~h}$, from 06:00 UTC to 12:00 UTC of 24 May, using a nudging time of $3 \mathrm{~h}$. Perturbations are added to the RM 38 above $500 \mathrm{hPa}$.

The inversion technique is the same as Davis and Emmanuel (1991) and was already adopted for studies in the Mediterranean basin (Fehlmann et al., 2000; Homar et al., 2000; Romero et al., 2005). The method consists of resolving an equation system for the geopotential $\phi$ and streamfunction $\psi$ formed by an approximate form of the Ertel PV, i.e. $q=\frac{1}{\rho} \eta \times \nabla \vartheta$ where $\rho$ is the air density, $\boldsymbol{\eta}$ is the absolute vorticity and $\theta$ is the potential temperature, and the nonlinear balance condition (Charney, 1955), which is very accurate for flows with large curvature. The Charney balance equation is obtained by taking the horizontal divergence of the horizontal momentum equation and decomposing the wind field into nondivergent and irrotational parts. Following Haltiner and Williams (1980), two Rossby numbers for the nondivergent and irrotational parts of the wind field are introduced given by $R_{\psi}=V_{\psi} / f L$ and $R_{\chi}=V_{x} / f L$, where $V_{\psi}$ and $V_{x}$ are the nondivergent and irrotational components of the velocity. Then, applying the scale analysis, the terms $O\left(R_{\psi}\right)$ are retained while the terms $O\left(R_{\chi}\right)$ and higher are neglected.
The resulting equations may be written in the following form:

$$
\begin{aligned}
& q=\frac{g k \pi}{p}\left[\left(f+m^{2} \nabla^{2} \psi\right) \frac{\partial^{2} \phi}{\partial \pi^{2}}-m^{2}\left(\frac{\partial^{2} \psi}{\partial x \partial \pi} \frac{\partial^{2} \phi}{\partial x \partial \pi}+\frac{\partial^{2} \psi}{\partial y \partial \pi} \frac{\partial^{2} \phi}{\partial y \partial \pi}\right)\right] \\
& \nabla^{2} \phi=\nabla \cdot f \nabla \psi+2 m^{2}\left[\frac{\partial^{2} \psi}{\partial x^{2}} \frac{\partial^{2} \psi}{\partial y^{2}}-\left(\frac{\partial^{2} \psi}{\partial x \partial y}\right)^{2}\right]
\end{aligned}
$$

where $g$ is the acceleration of gravity, $k=R / C_{p}, p$ is the pressure, $f$ is the Coriolis parameter, $\pi=C_{p}\left(p / p_{0}\right)^{k}$ is the Exner function, and $m$ is the map scale factor.

From an instantaneous distribution of PV and a boundary condition set, the three-dimensional distributions of $\phi$ and $\psi$ are obtained. Dirichlet upper and bottom boundary conditions are used in solving the system of nonlinear balanced flow following $\partial_{\pi} \phi=-\vartheta$. The three dimensional temperature is derived from the hydrostatic balance.

Figure 7 shows the PV for the 00 forecast and for the RM 38 on the $330 \mathrm{~K}$ isentropic surface. The thick solid line indicates the 2.0 PVU of the unperturbed forecast. This line roughly corresponds to the shape of the PV anomalies, identified above $500 \mathrm{hPa}$, that were inverted to perturb the RM 38 simulation.

Figure 8 shows the geopotential height and temperature fields for the RM 38 and RM 38p forecast at 12:00 UTC on 24 May. The effect of PV perturbation is a shift of the upper level cutoff toward southeast. Temperature perturbations enhance the stability in correspondence of the cutoff by warming above the low and cooling below. This results in a shifting of the dynamic forcing pattern for the sea level mesolow that forms over the Ionian sea. Figure 9 shows the sea level 


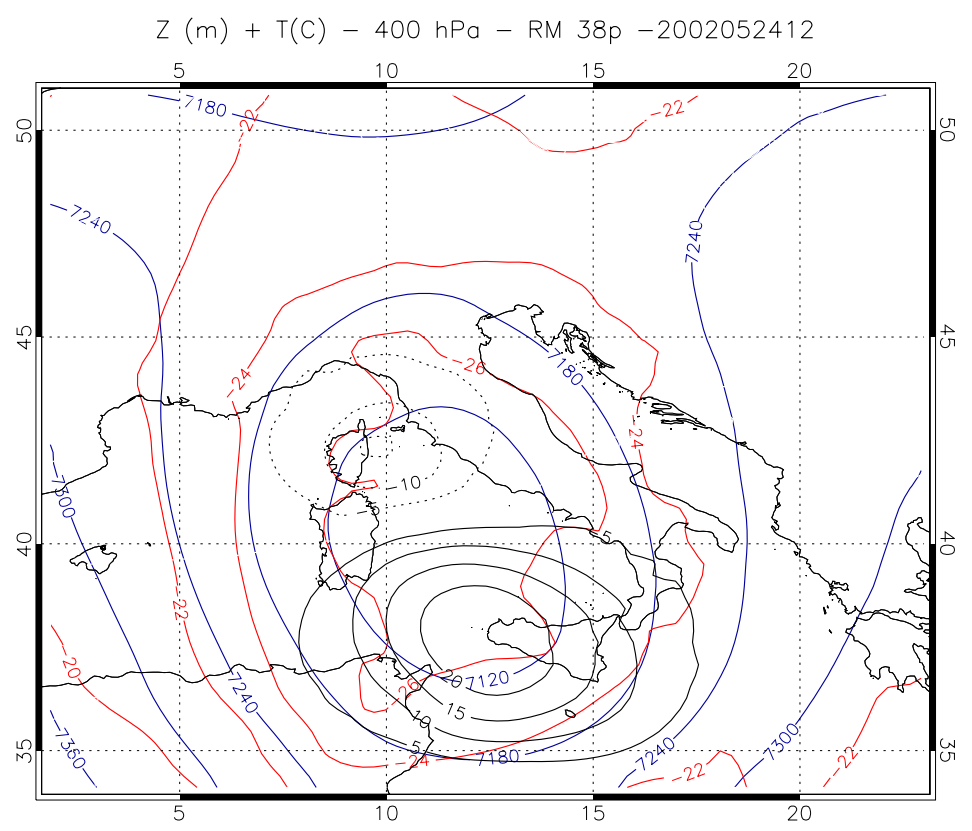

Fig. 8b. As in Fig. 8a for the RM 38p forecast. Differences between RM 38 and RM 38p geopotential height are also reported: solid black lines are positive contours (form $5 \mathrm{~m}$ to $20 \mathrm{~m}$ every $5 \mathrm{~m}$ ), dotted lines are negative contours (from $-5 \mathrm{~m}$ to $-15 \mathrm{~m}$ every $5 \mathrm{~m}$ ).

pressure, the $925 \mathrm{hPa}$ wind and the instantaneous rainfall rate at 00:00 UTC on 25 May for the RM 38 and RM 38p forecast. The mesolow of the perturbed run is shifted to the south and is closer to Calabria peninsula compared to the RM 38 simulation. This results in a different low level flow that impinges Calabrian littoral with changes in the associated precipitation pattern.

Figure 10a shows the accumulated precipitation for the RM 38p, and Fig. 10b shows the precipitation difference between the RM 38 and the RM 38p forecasts. Compared to the RM 38 (Fig. 5) the RM 38p rainfall is greater over southern Calabria and over the western side of the peninsula, while it is reduced on the east side. Stated in other terms, RM 38p clearly recovers part of the intensity, abundance and pattern of the RM 00.

Additional sensitivity simulations were conducted by perturbing the RM 00 with PV key filaments derived from the difference between the fields of RM 00 and RM 50, and from RM 00 and RM 38 and adding the inverted fields to the unperturbed forecast, following the same methodology illustrated above. In both simulations the precipitation field of the RM 00p (perturbed simulation 00) recovers part of the signature of the perturbing RM, i.e. RM 38 in the first case and RM 50 in the second case. We conclude, then, that the shape, abundance, and timing of rainfall precipitation for this moderate-intense event was strongly tied to the uppertropospheric forcing, associated with the PV filament.

\section{Conclusions}

This study investigates RAMS model quantitative precipitation forecast performance for a moderate-intense rainstorm that occurred in southern Italy. It adopts a potential vorticity perspective. Results of simulations that employ a potential vorticity inversion procedure verify the working hypothesis that precipitation pattern is sensible to the upper-tropospheric forcing in terms of timing, abundance and pattern.

The study also explored the possibility of improving RAMS forecasts by a subjective analysis and comparison between the METEOSAT WV images and the model output pseudo water vapour images. Different scenarios are selected starting from ECMWF-EPS, and results show that, for this case study, the forecast could have been clearly improved, if those images had been available. Although based on only a single case study, this preliminary study is encouraging and additional simulations are underway to better define its reliability.

Acknowledgements. This work was partially funded by "Ministero dell'Università e della Ricerca Scientifica" under the projects "SAI - Messa a punto di un Sistema per l'Allerta precoce di Incendi e per la minimizzazione dei falsi allarmi" and "TAI - Tecniche Agronomiche Innovative per la valorizzazione delle produzioni ed il miglioramento della qualità ambientale". We are grateful to the Italian Air Force and ECMWF for a MARS database account We wish to thank the reviewer for constructive comments, which helped to clarify and improve the paper.

Edited by: P. Alpert, H. Saaroni, and E. Heifetz Reviewed by: S. Krichak 


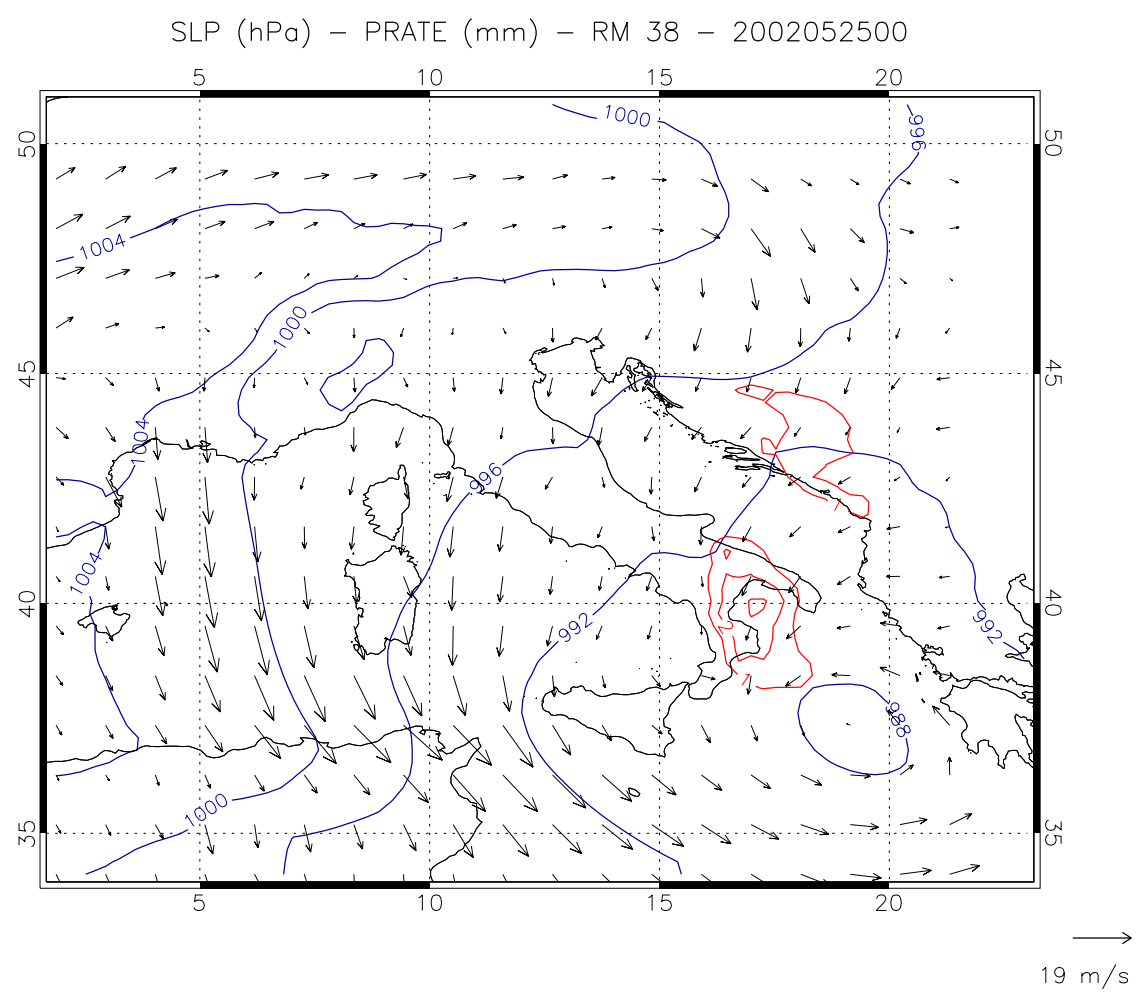

Fig. 9a. Sea level pressure (hPa, blue line), precipitation rate ( $\mathrm{mm} / \mathrm{h}$, red line) and wind field at $925 \mathrm{hPa}$ for the RM 38 forecast on 00:00 UTC 25 May 2002.

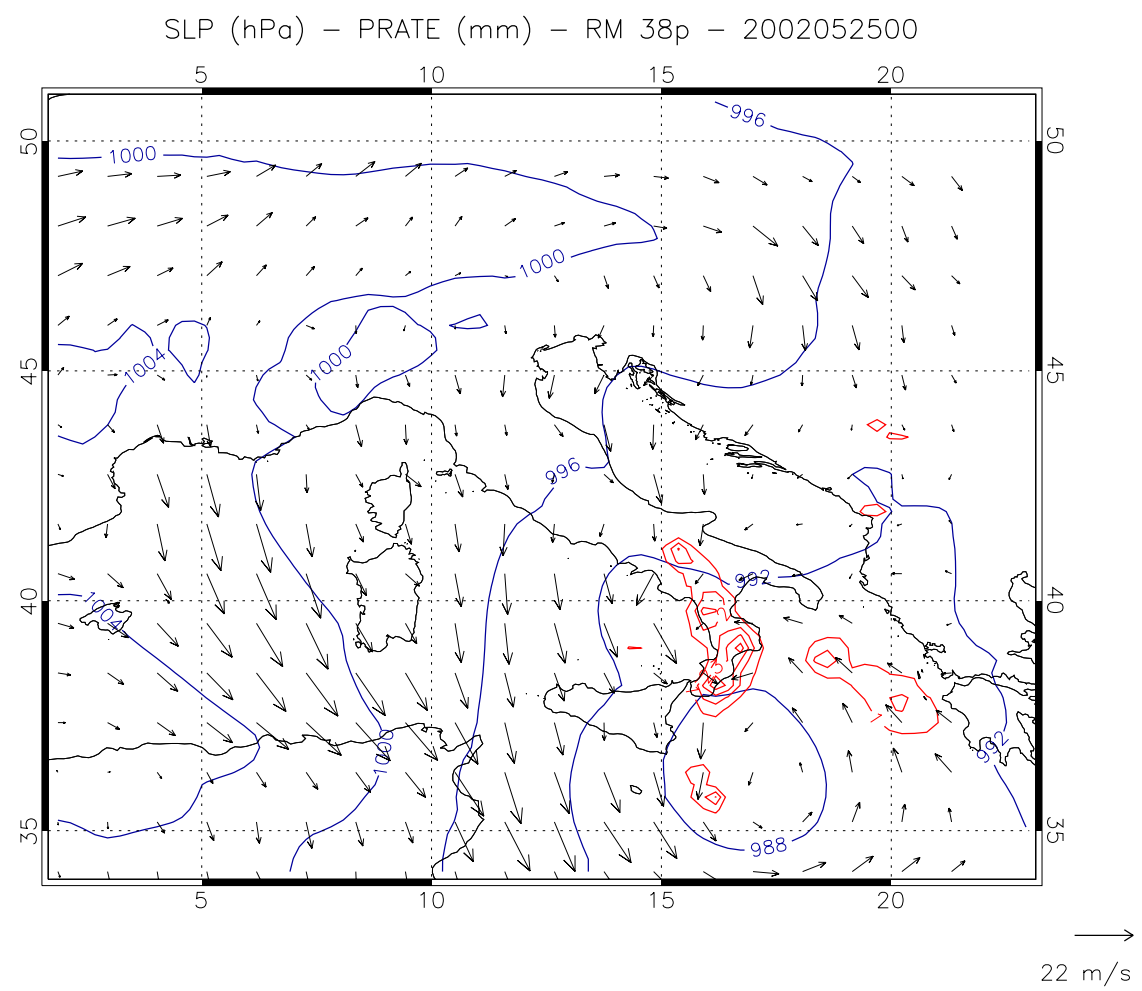

Fig. 9b. As in Fig. 9a for the RM 38p forecast. 


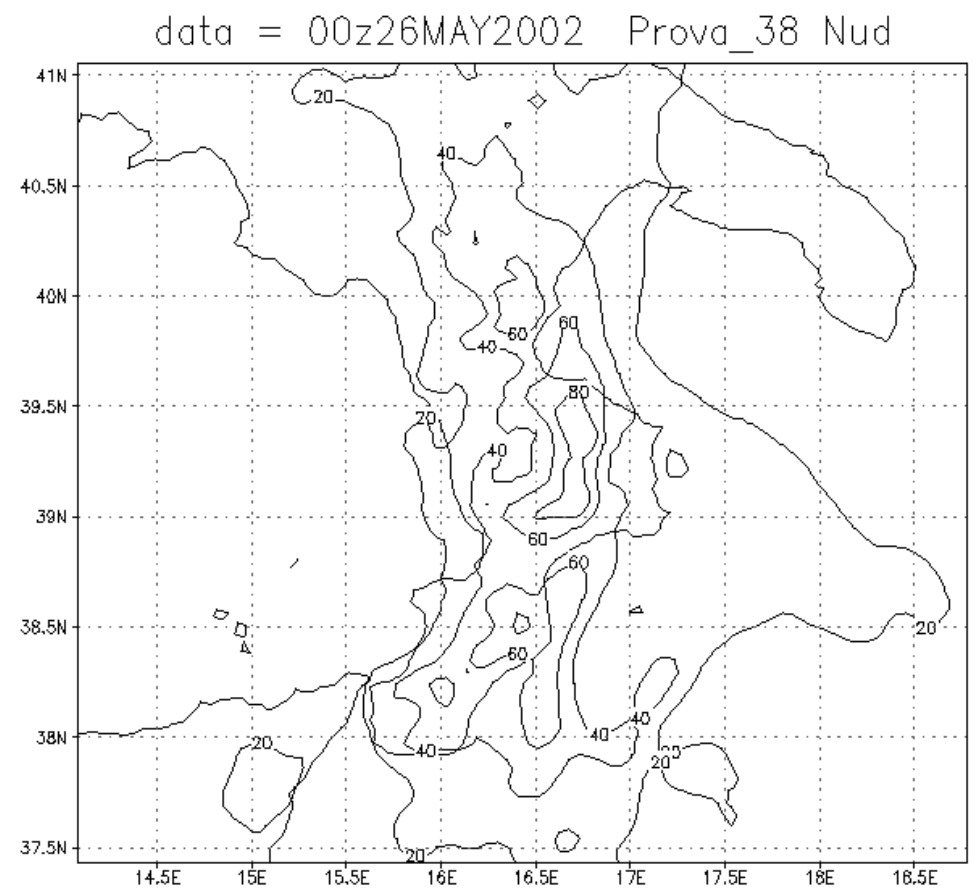

GrADS: COLA/IGES

$2005-10-05-15: 47$

Fig. 10a. Total accumulated precipitation ( $\mathrm{mm}$ ) for the perturbed forecast RM 38p over the same time frame as Fig. 4. Contours are reported every $20 \mathrm{~mm}$ starting from $20 \mathrm{~mm}$.

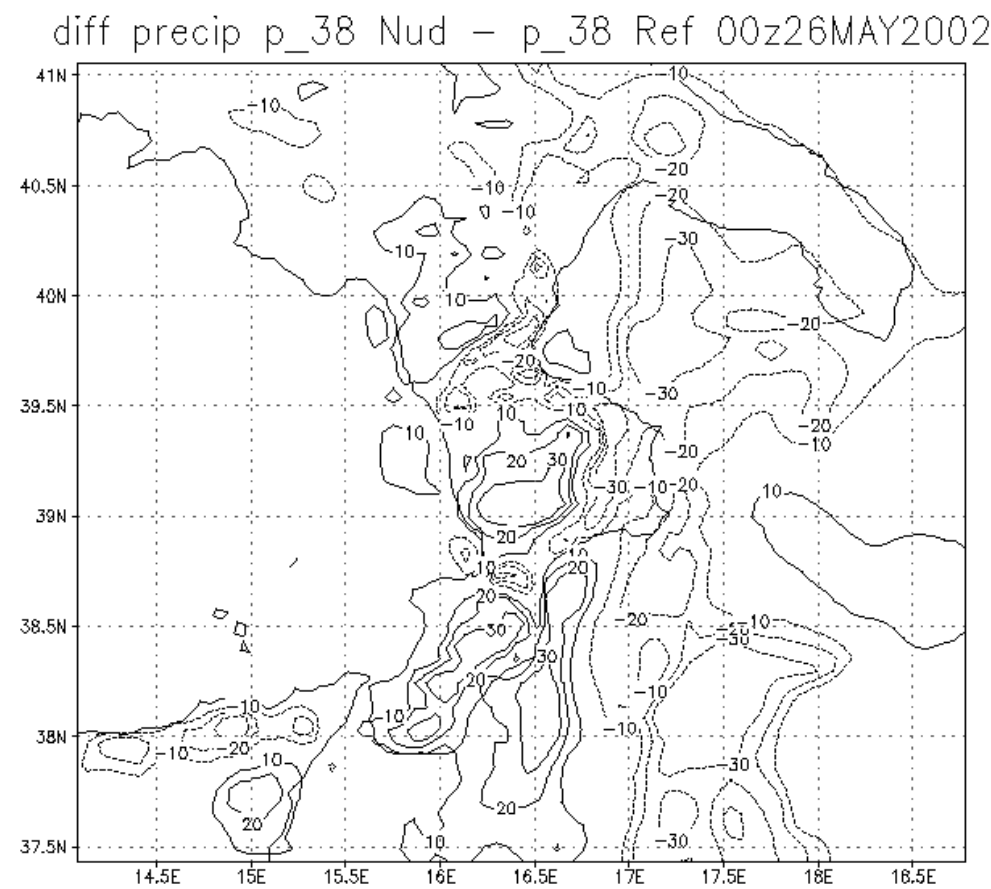

GrADS: COLA/IGES

$2006-10-05-15: 55$

Fig. 10b. Difference between accumulated precipitation $(\mathrm{mm})$ for the perturbed forecast RM 38p and the RM 38 . Dashed contours: -30 mm, $-20 \mathrm{~mm}$ and $-10 \mathrm{~mm}$; solid contours: $10 \mathrm{~mm}, 20 \mathrm{~mm}, 30 \mathrm{~mm}$. 


\section{References}

Alpert, P. and Coauthors: The paradoxial increase of Mediterranean extreme daily rainfall in spite of decrease in total values, Geophys. Res. Lett., 29, 1536-1540, 2002.

Buzzi, A. and Tibaldi, S.: Cyclogenesis on the lee of the Alps: A case study, Q. J. Roy. Meteor. Soc., 104, 271-287, 1978.

Buzzi, A. and Foschini, L.: Mesoscale meteorological features associated with heavy precipitation in the southern Alpine region, Meteor. Atmos. Phys., 72, 131-146, 2000.

Charney, J. G.: The use of primitive equations of motions in numerical prediction, Tellus, 7, 22-26, 1955.

Cotton, W. R., Pielke Sr., R. A., Walko, R. L., Liston, G. E., Tremback, C. J., Jiang, H., McAnelly, R. L., Harrington, J. Y., Nicholls, M. E., Carrio, G. G., and McFadden, J. P. : RAMS 2001: Current satus and future directions, Meteor. Atmos., 82, 5-29, 2003.

Davis C. A. and Emmanuel, K.: Potential vorticity diagnosis of cyclogenesis, Mon. Wea. Rev, 119, 1929-1953, 1991.

Federico, S., Bellecci, C., and Colacino, M.: Quantitative precipitation of the Soverato flood: the role of orography and surface fluxes, Nuov. Cim. C, 26C, 7-22, 2003.

Federico, S., Avolio, E., Bellecci, C., Colacino, M., and Walko, R. L.: Application of the LEPS technique for Quantitative Precipitation Forecasting (QPF) in southern Italy: a preliminary study, Nonlin. Processes Geophys., 13, 53-66, 2006, http://www.nonlin-processes-geophys.net/13/53/2006/.

Fehlmann, R. and Davies, H. C. : Role of salient potential vorticity elements in an event of frontal-wave cyclogenesis, Q. J. Roy. Meteor. Soc., 125, 1801-1824, 1999.

Fehlmann, R., Quadri, C., and Davies, H. C.: An Alpine rainstorm: Sensitivity to the mesoscale upper level structure, Wea. Forecast., $15,4-28,2000$.

Haltiner, G. J. and Williams, R. T.: Numerical prediction and dynamic meteorology, Second Edition, John Wiley \& Sons, New York, 1980.
Hoskins, B. J., McIntyre, M. E., and Robertson, A. W.: On the use and significance of isentropic potential vorticity maps, Q. J. Roy. Meteor. Soc., 111, 877-946, 1985.

Homar, V., Ramis, C., and Alonso, S.: A deep cyclone of African origin over the Western Mediterranean: diagnosis and numerical simulation, Ann. Geophys., 20, 93-106, 2001, http://www.ann-geophys.net/20/93/2001/.

Krichak, S. O., Alpert, P., and Dayan, M.: A southeastern Mediterranean PV streamer and its role in December 2001 case with torrential rains in Israel, Nat. Hazards Earth Syst. Sci., 7, 21-32, 2007, http://www.nat-hazards-earth-syst-sci.net/7/21/2007/.

Molinari, J. and Corsetti, T.: Incorporation of cloud-scale and mesoscale down-drafts into a cumulus parametrization: results of one and three-dimensional integrations, Mon. Wea. Rev., 113, 485-501, 1985.

Romero, R., Martín, A. , Homar, V., Alonso, S., and Ramis, C.: Predictability of prototype flash flood events in the Western Mediterranean under uncertainties of the precursor upper-level disturbance: The HYDROPTIMET case study, Nat. Hazards Earth Syst. Sci., 5, 505-525, 2005, http://www.nat-hazards-earth-syst-sci.net/5/505/2005/.

Romero, R., Martín, A., Homar, V., Alonso, S., and Ramis, C.: Predictability of prototype flash flood events in the Western Mediterranean under uncertainties of the precursor upper-level disturbance, Adv. Geosci., 7, 55-63, 2006, http://www.adv-geosci.net/7/55/2006/.

Siccardi, F.: Rainstorm hazards and related disasters in the western Mediterranean region, Rem. Sens. Rev., 14, 5-21, 1996.

Walko, R. L., Band, L. E., Baron, J., Kittel, T. G., Lammers, R., Lee, T. J., Ojima, D., Pielke Sr., R. A., Taylor, C., Tague, C., Tremback, C. J., and Vidale, P. L.: Coupled Atmosphere-BiosphereHydrology Models for environmental prediction, J. Appl. Met., 39, 931-944, 2000. 